\title{
Sensitivity Analysis of Common Input Parameters in Tools for Modeling Energy in Homes
}

\author{
Sheikh Tijan Tabban, Nelson Fumo* \\ Department of Mechanical Engineering, The University of Texas at Tyler, Tyler, TX \\ Student:stabban@patriots.uttyler.edu \\ Mentor:*nfumo@uttyler.edu
}

\begin{abstract}
Energy models of buildings can be developed and used for analysis of energy consumption. A model offers the opportunity to simulate a building under specific conditions for analysis of energy efficiency measures or optimum design. Due to the great amount of information needed to develop an energy model of a building, the number of inputs can be reduced by making variable the most relevant input parameters and making the others to take common or standard values. In this study, an analysis of input parameters required by computational tools to estimate energy consumption in homes was done in two stages. In the first stage, common input parameters were identified for three software and three webtools based on the criteria that the input parameter should be common for at least two software and at least one webtool. In the second stage, a sensitivity analysis was performed on the inputs identified in the first stage. The software BEopt, developed by the National Renewable Energy Laboratory, was used as the source of typical input parameters to be compared, and to perform the simulations for the sensitivity analysis. The base or reference model to perform simulations for the sensitivity analysis corresponds to a model developed with information from a research house located on the campus of the University of Texas at Tyler and default inputs for the BEopt B-10 reference benchmark. Results show that besides the location, and consequently the weather, common parameters are building orientation, air leakage, space conditioning settings, space conditioning schedule, water heating equipment, and terrain. Among these parameters, the sensitivity analysis identified the largest variations in energy consumption for variations on space conditioning schedule (heating and cooling setpoints), followed by the type of water heating equipment.
\end{abstract}

\section{KEYWORDS}

Residential Buildings; Energy Consumption; Energy Analysis; Input Parameters; Building Simulation; Source Energy

\section{INTRODUCTION}

Energy efficiency in the residential sector has collected a strong interest in developed countries like United States and Canada because of the amount of energy consumed by this sector. In the United States the residential sector accounts for about $22.2 \%$ of the total energy consumption ${ }^{1}$, while in Canada it is about $17 \%{ }^{2}$. The United States National Renewable Energy Laboratory $\left(\mathrm{NREL}^{3}\right.$ and Canada's agency CanmetENERGY 4 investigate and promote ways to reduce the energy intensity of residential and commercial buildings. One way to do this is by creating computational tools capable of modeling building energy performances accurately. All tools need inputs that allow a description of the building in the model development. However, based on the approach used to develop the model, that is engineering, statistical, or hybrid ${ }^{1}$, more or less inputs are needed.

Energy models can help to identify building characteristics that can reduce energy consumption while maintaining economic feasibility. As an example, in an attempt to better understand the balance between investment costs, energy consumption, and indoor environment quality in high rise residential buildings in China, Zhao et. al. ${ }^{5}$ used dynamic simulations to investigate the influence of envelope design parameters on energy demands for heating and cooling reduction. Their results allowed them to conclude that the most sensitive design parameters where air tightness and insulation thickness of external walls. They also stated that window to wall ratio on the south façade, and building orientation can help to reduce energy demand.

To estimate energy consumption in buildings two approaches can be utilized: bottom-top or top-down. This work is related to energy models of individual buildings that can be used later for a bottom-top approach. In this sense, as mentioned by Arababadi et al. ${ }^{6}$, engineering models can be used to calculate the energy demand of individual buildings with input parameters associated to physical characteristics and energy end uses (e.g., lighting, appliances, and water heating). Then, those results can be used to scale up the results to represent the building stock of the region studied. Based on this approach, they investigated the use of a stepwise regression approach as a means to substitute the time consuming sensitive analysis used to identify relevant parameters. They mention that the literature suggests that the level of complexity of energy models needs to be limited and the accuracy of models 
can be increased by reducing the number of input parameters by avoiding the assumptions made for factors such as building construction and occupancy, among others. As a conclusion, they stated that the stepwise regression approach can help to identify the most relevant inputs, making possible to reduce the number of inputs which facilitates the use of the model and simulations.

From another point of view, codes and standards can be used as a reference on what is needed to satisfy residential prescriptive requirements. For example, the International Energy Conservation Code ${ }^{7}$ for residential energy efficiency defines requirements based on three categories: building thermal envelope, systems, and electrical power and lighting systems. While ASHRAE standards $^{8}$ defines recommended parameters based on four categories: envelope, lighting, HVAC, and service water heating (SWH). In general, for envelope, the R-value and U-value are the parameters considered, for lighting, the power density, and for HVAC and SWH, the efficiency is the parameter prescribed.

There is a great amount of input parameters that are needed to create the energy model of a building. However, simplifications could be made based on the objective of the model. As discussed by Urban and Glicksman', for an early design stage simplification of the modeling process using a user-interface makes a simulation tool accessible to a wider audience. Based on this justification, they developed the tool MIT Design Advisor to assist the users, such as architects, to investigate which design factors can save the most energy without affecting thermal comfort. The MIT Design Advisor tool uses zone configuration, building location and orientation, room dimensions and orientation, windows characteristics, wall insulation, thermal mass, occupancy (occupancy density and schedule, equipment load, and lighting), and ventilation (natural or mechanical) as the basic input options. Their preliminary trials have shown encouraging results.

In a model, the impact of an input parameter on the total energy consumption is different from one parameter to another. So, a sensitive analysis can be used to identify the parameters with the greatest impact. For example, Ioannou and L. Itard ${ }^{10}$ performed a Monte Carlo sensitivity analysis on building and occupant behavior factors affecting annual heating energy consumption in Northern Europe. They found that when the behavioral parameters were not taken into account, the most critical parameters were the window $\mathrm{U}$-value, window transmittance, and wall conductivity. With the impact of the wall conductivity being the most significant parameter when the uncertainty of the building-related parameters increases. When behavioral parameters like thermostat setpoints and ventilation flow rate are considered in the analysis, they diminish the importance of the building parameters.

Reports as those mentioned previously, motivated this study with the idea of identifying the minimum number of relevant input parameters to support the development of hybrid models with the intention of developing a simple tool for estimating residential energy consumption. Therefore, input parameters used in energy analysis of residential buildings are compared by several tools. The main source of these tools was the Building Energy Software Tools Directory ${ }^{11}$, which provides a large list of software tools for evaluating building energy efficiency, renewable energy, and sustainability in buildings. The main criterion for the selection among the available software tools was to select only those free of charge. Among the software tools identified, the Building Energy Optimization (BEopt) software ${ }^{12}$ was chosen to be the base template for comparing the input parameters. BEopt was chosen because of its relevance and continuous development by NREL with the support of the U.S. Department of Energy through the Building America Program ${ }^{13}$, and because of its simplicity to develop the building geometry and selection of input parameters from common options. The impact of common input parameters on energy consumption was assessed through a sensitivity analysis using the input parameters of the B-10 benchmark as the reference. The B-10 benchmark is a model in BEopt based on the 2009 International Energy Conservation Code and the Building America protocol.

The geometry and weather considerations for this study are based on the TxAIRE House \#1 located on the campus of the University of Texas at Tyler. The Texas Allergy, Indoor Environment, and Energy Institute (TxAIRE) has two houses designed to serve as realistic test facilities for developing and demonstrating new technologies related to energy efficiency, indoor air quality, and the sustainable construction material methods. ${ }^{14}$

\section{MATERIALS AND METHODS}

Software and Webtools

Based on inputs accessibility from software and webtools consulted, the list below is the software and webtools used for the comparison of the input parameters in residential buildings.

Software:

- $\quad$ BEopt (Building Energy Optimization)

- EnergyGauge

- Home Energy Saver 
Webtools:

- Home Energy Yard Stick

- Home Energy Scoring Tool

- Hot2 XP

The following is a description of each one of them:

BEopt

BEopt (Building Energy Optimization) ${ }^{12}$ is a free software developed by the National Renewable Energy Laboratory under the support of the U.S. Department of Energy through the Building America Program. The software provides the capability to analyze residential building designs and the entire cost of the efficiency platform of an entire building calculating the energy savings along with the path to zero net energy. It can also be used to analyze both old and new buildings using the evaluation of single building designs, parametric sweeps, and cost based optimization according to the BEopt website. BEopt also provides detailed simulation based on the house characteristics. BEopt uses EnergyPlus ${ }^{15}$ as simulation engine to run simulations with an hour by hour time-step.

\section{EnergyGauge}

EnergyGauge ${ }^{16}$ was developed by the Florida Solar Energy Center of the University of Central Florida, partnering with the U.S. Environmental Protection Agency and the U.S. Department of Energy (EPA). EnergyGauge can be used for both residential and commercial buildings, and currently EnergyGauge software uses version 4 for residential buildings and version 5 for commercial buildings. The EnergyGauge software is not free, but since it is recognized and used for energy audits and design of low energy homes, it was added to this study. This software can be used for residential buildings energy analysis and can also be used for improvement and economic analysis of existing buildings. The developers state that EnergyGauge can provide accurate computation of heating and cooling system part load performance, accurate prediction of indoor air relative humidity, and hourly prediction of end-use electrical and gas energy consumption for evaluation of peak impacts. The developers also state that the software has the ability to compute whole house mechanical ventilation system including run time ventilation, dehumidifiers, solar thermal system, and photovoltaic system. ${ }^{16}$ Energy Gauge offers a free trial period; it was sufficient time to record the input parameters that was needed for the comparison.

\section{Home Energy Saver}

Home Energy Saver (HES) ${ }^{17}$ computes a home's energy use on-line in a matter of seconds based on models and data developed at the U.S. Department of Energy's Lawrence Berkeley National Laboratory. According to the developers HES empowers homeowners and renters to save money, live better, and help the earth by reducing energy use in their homes. HES recommends energy saving upgrades that are appropriate to the home and make sense for the home's climate and local energy prices. The money invested in these upgrades commonly earns "interest" in the form of energy bill savings, at an annual rate of $20 \%$ or more. HES also estimates the home's carbon footprint and shows how much it can be reduced. As well, HES generates a list of energysaving upgrade recommendations for the user's consideration. The upgrades recommended by HES offer other benefits as well. Depending on the type of improvement made, the homeowner can achieve better comfort (warmer in winter, cooler in summer), fewer drafts, lower maintenance costs, and improved security and fire safety that improve life and increase the home's value.

\section{Home Energy Yardstick}

ENERGY STAR is a voluntary program from EPA that helps businesses and individuals save money and protects the climate through superior energy efficiency. Home Energy Yardstick was developed by Energy Star in collaboration with EPA. Home Energy Yardstick ${ }^{18}$ provides a simple assessment of a building's annual energy use in comparison to similar buildings. By answering a few basic questions about the home, the home's Home Energy Yardstick score can be obtained. Insights include how much of the home's energy usage is related to heating and cooling versus other everyday uses like appliances, lighting, and hot water. Links to guidance from ENERGY STAR provide data on how to increase home's score, improve comfort, lower utility bills, and an estimate of your home's annual carbon emissions. ${ }^{12}$

\section{Home Energy Scoring Tool}

The Home Energy Score ${ }^{19}$ is a national rating system developed by the U.S. Department of Energy; it allows Qualified Assessors to generate clear, credible home energy assessments at a reasonable cost. The Score reflects the energy efficiency of a home based on the home's structure, heating and cooling, and hot water systems. The Home Facts provide details about the current structure and systems. Recommended customized upgrades and saving tips help consumers compare the energy use of different homes to their own. The home energy scoring tool is not free and requires a qualified assessor to access the home energy scoring tool 
website. Qualified assessors can gather the information needed to assess a home in one short online visit. This low-cost, high value assessment can be provided as a stand-alone service or as an add-on to a home inspection or comprehensive energy assessment. A free pdf of the input parameters was provided by the Home Energy Scoring Tool website to allow future users to see the sample of the input parameters. ${ }^{13}$

\section{HOT2®XP}

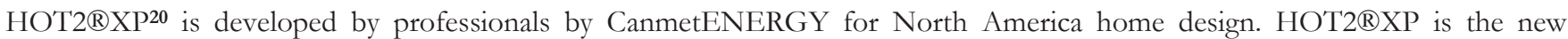
software created to replace Hot2000, however the underlying engine is that of HOT2000 and thus provides a state-of-the-art analysis. Its graphical user interface and simplified input make it a quick and easy tool for analyzing energy use in houses. HOT2®XP is also used as the compliance software for the Canadian Energy Guide for House Programs.

HOT2 ${ }^{\circ} \mathrm{XP}$ forecasts energy consumption for residential construction projects accurately; it predicts energy cost and performance of natural gas, electric, propane, oil and wood heating equipment; and calculates thermal resistance of envelope components, including thermal bridging of construction materials. The data for the HOT2®XP is entered through a menu-driven interface and internal structural libraries provide many defaults inputs. According to the developers, the user can override these defaults and add additional details, which will increase the accuracy of the analysis. The software tools enable users to assess various types of renewable energy and energy efficient technologies to meet Canada's clean air and greenhouse gas emissions objectives. They increase the industry's ability to optimize integrated energy efficient design in domestic and international markets, reduce operating costs, comply with code requirements, and qualify for funding and incentive programs. ${ }^{21}$

\section{Input Variable Matrix}

For the comparison of the input parameters for the different software and webtools selected for this study, a matrix was created to ease the comparison. Three software and three webtools were selected based on the free access to the inputs information.

The matrix developed is presented in the Appendix. The matrix is divided into nine columns, the first column is the category column where input options from the geometry screen, options screen, and site screen of the BEopt are indicated. The second column is a subcategory section, and the third column is the option column. The software and webtools are identified in the columns from the fourth to the ninth columns where the comparison takes place. The common input parameters, based on the stated criteria, are summarized as building orientation, air leakage, space conditioning settings, space conditioning schedule, water heating settings, and type of terrain.

\section{RESULTS}

\section{Sensitivity Analysis}

Sensitivity analysis was performed for the inputs identified and is listed in the previous section. The sensitivity analysis was done by running simulations with defined variations in each input parameter and comparing the source energy use with respect to the B-10 benchmark reference. The weather file used in all simulations corresponds to the Tyler Pounds Field (regional airport). For each input parameter considered, simulation results are presented in a table. For all tables, source energy use in millions of Btu per year (MMBtu/yr) and percentage variation are shown. The variation corresponds to the reduction (positive percentage) or increase (negative percentage) of the energy use when compared to the B-10 benchmark model. The energy systems are as given by the results from BEopt simulations, with (E) indicating electricity and $(\mathrm{G})$ natural gas. From all tables, it can be seen that the results show that energy use from some of the energy systems are not affected by the changes on the input parameters investigated. These energy systems are miscellaneous equipment (electricity or natural gas), ventilation fans, and large appliances. Lights do not show variations for any of the investigated inputs, and possible variations due to building orientation are not captured by the simulations because of the fixed lighting schedule.

\section{Variations in orientation settings}

In the B-10 benchmark settings, the orientation is North $(\mathrm{N})$, which is the same of the TxAIRE House \#1. Simulations were performed for the following sequence of house orientation variations: South (S), East (E), West (W), South-East (SE), SouthWest (SW), North-West (NW), and North East (NE). Results for this input are shown in Table 1. The results illustrate that the energy use from energy systems associated to the HVAC system are affected by building orientation mainly because of the variation of load due to exposure of walls and windows to solar radiation. The impact of the orientation will depend on the windows' area in each façade facing a cardinal direction. Since it is generally accepted that the long axis of a house should run east-west to reduce energy use, it can be noted that the larger energy reductions of $0.7 \%$ is achieved for the western orientation. On the other hand, the north-east orientation illustrates the typical inverse variation in heating and cooling loads found from changes in orientation. For the simulated house, the cooling load decreased by $1.2 \%$, but the heating load increased by $1.2 \%$. 


\section{Variations in air leakage settings}

Variations in air leakage are defined as air changes at a pressure of $50 \mathrm{kPa}$ (ACH 50). In the B-10 benchmark settings, the air leakage default option is the $7 \mathrm{ACH}-50$. Simulations correspond to the following sequence of options change on air leakage: 6 ACH-50, 5 ACH-50, 4 ACH-50, 3 ACH-50, 2 ACH-50, and, 1 ACH-50. Results for this input are shown in Table 2. The results illustrate that the energy use from energy systems associated to the HVAC system are affected by the air leakage due to the additional load that air leakage implies. As the air leakages are reduced, the energy usage is reduced. It can be noted that an energy reduction of about $0.3 \%$ can be achieved by reducing the leakages by one category; for example, from $\mathrm{ACH}-4$ to $\mathrm{ACH}-3$ there is a reduction from $0.5 \%$ to $0.8 \%$ when compared to the benchmark (B-10_ACH-7). For this study, the maximum reduction of $1.7 \%$ was achieved for the air leakage setting of ACH-1.

\section{Variations in space conditioning settings}

In the B-10 benchmark settings, the default option corresponds to Central Air Conditioner (A/C) with efficiency of SEER 13 and gas Furnace with efficiency of 78\%. Table 3a shows results for variations in the A/C efficiency as SEER 14 (A/C-14) and SEER 15 (A/C-15), without changes in the furnace. Table $3 \mathbf{b}$ shows results for changing the A/C and furnace by an Air Source Heat Pump (HP) with different efficiencies: SEER 13 (HP-13), SEER 14 (HP-14), and SEER 15 (HP-15). Results from Table 3a show the energy usage associated with the HVAC system, which is affected mainly by the variation of the load due to the seasonal energy efficiency factor (SEER). As the efficiency of the air conditioning unit increases, the energy used will decrease. A maximum energy reduction of $1.9 \%$ was achieved by using an air conditioning unit with a rating of SEER-15. Similarly, results from Table 3b show the energy usage associated with the HVAC system but with variations due to Heating Seasonal Performance Factor (HSPF) and the SEER of the heat pump. As the efficiency of the air source heat pump increases, the energy used decreases. For this study, the maximum reduction of 5.6 \% was achieved for the air source heat pump setting of SEER-15. It can be noted that for the same SEER, a heat pump gave a greater energy reduction than the A/C-furnace $(5.6 \%$ compared to $1.9 \%)$.

\section{Variations in space conditioning schedule}

This sensitivity analysis was done by changing the cooling setpoint and heating setpoint for the space conditioning schedule. In the B-10 benchmark settings, the default option corresponds to $76^{\circ} \mathrm{F}$ and $71^{\circ} \mathrm{F}$ for the cooling and heating setpoints, respectively. Table 4a shows results where the cooling setpoint was decreased and the heating setpoint was increased as follows: $75^{\circ} \mathrm{F} / 72^{\circ} \mathrm{F}$, $74^{\circ} \mathrm{F} / 73^{\circ} \mathrm{F}, 73^{\circ} \mathrm{F} / 74^{\circ} \mathrm{F}$, and $72^{\circ} \mathrm{F} / 75^{\circ} \mathrm{F}$. While Table $4 \mathrm{~b}$ shows results where the cooling setpoint was increased and the heating setpoint was decreased as follows: $77^{\circ} \mathrm{F} / 70^{\circ} \mathrm{F}, 78^{\circ} \mathrm{F} / 69^{\circ} \mathrm{F}$, and $79^{\circ} \mathrm{F} / 68^{\circ} \mathrm{F}$. As expected, the energy use increased when the set point for cooling is lowered and the set point for heating is raised. This is due to the fact that the difference between the indoor and outdoor temperatures increase, which is the driving force for heat transfer. Table 4a illustrates that the energy used by the systems associated to the HVAC systems are affected by the variation of the load due to the decrease in cooling and increase in heating setpoints settings. It can be noted that there was an increase in the energy used when compared to the B-10 benchmark, with a maximum increment of $17.5 \%$ for the cooling/heating setting of $72^{\circ} \mathrm{F} / 75^{\circ} \mathrm{F}$. Similarly, Table $4 \mathrm{~b}$ illustrates that the energy used from the system associated to the HVAC systems are affected by the increase in cooling and decrease in heating setpoints settings. A decrease in the energy use was noted when compared to the B-10 benchmark, with a maximum reduction of $10.2 \%$ for the cooling/heating setting of $79^{\circ} \mathrm{F} / 68^{\circ} \mathrm{F}$.

\section{Variations in water heating settings}

In the B-10 benchmark settings, the default option correspond to a gas water heater. Variations were set by changing the options. Table 5 shows results for the following water heater options: gas tankless water heater (GTWH), electric standard water heater (ESWH), electric tankless water heater (ETWH), and heat pump water heater (HPWH). As generally known, a gas tankless water heater consumes less energy than a standard gas water heater. This is due to the reduction of wasted heat through the walls of the storage tank. From the simulation results given in Table 5, the reduction in source energy consumption was found to be $27.1 \%$ and $3.4 \%$ for the water heater itself and the total energy usage, respectively. As expected, changing from gas to electricity increases the source energy consumption. For the standard and tankless electric water heaters, the source energy usage increased $77.9 \%$ and $74.6 \%$ for the water heater itself, respectively. While the source energy usage increased $10 \%$ and $9.7 \%$ with respect to the total energy usage. Results of the heat pump water heater show that this type of water heater reduces the energy consumption. The reduction in source energy consumption was found to be $3.6 \%$ and $0.4 \%$ for the water heater itself and the total energy usage, respectively. It can be noted that the energy consumption associated to cooling was reduced, while the energy consumption associated to heating was increased. This can be explained because the heat pump water heater will take heat from the house to heat the water. During the summer this is in favor of the HVAC system, but it is against it during the heating season.

\section{Variations in type of terrain}

In the B-10 benchmark settings, the default option corresponds to the suburban terrain, which match the terrain type the TxAIRE House \#1 is located. For the sensitive analysis, simulations were performed for each option available in BEopt: 
suburban, city, rural, plains, and oceans. Table 6 shows the results for the terrain options. The terrain option is used in simulations to modify the local free stream wind speed to account for ground roughness. This affects the wind speed at the building and the resulting air infiltration, as well as convection heat transfer coefficients. This effect is noticed in the HVAC performance on both cooling and heating and associated fan energy. For cooling energy, an increase in energy is found for the city option, but a reduction of energy is found for the rural, plains, and oceans options. For heating, the contrary effect appears, a reduction in energy is found for the city option, but an increase of energy is found for the rural, plains, and oceans options. Since the weather file used in the simulations is for the specific location of Tyler Pounds field, results should be used to infer upon the increase or decrease of energy usage but not on the magnitude. This is particularly true for the oceans option because the wind speed is higher on the coast compared to inland.

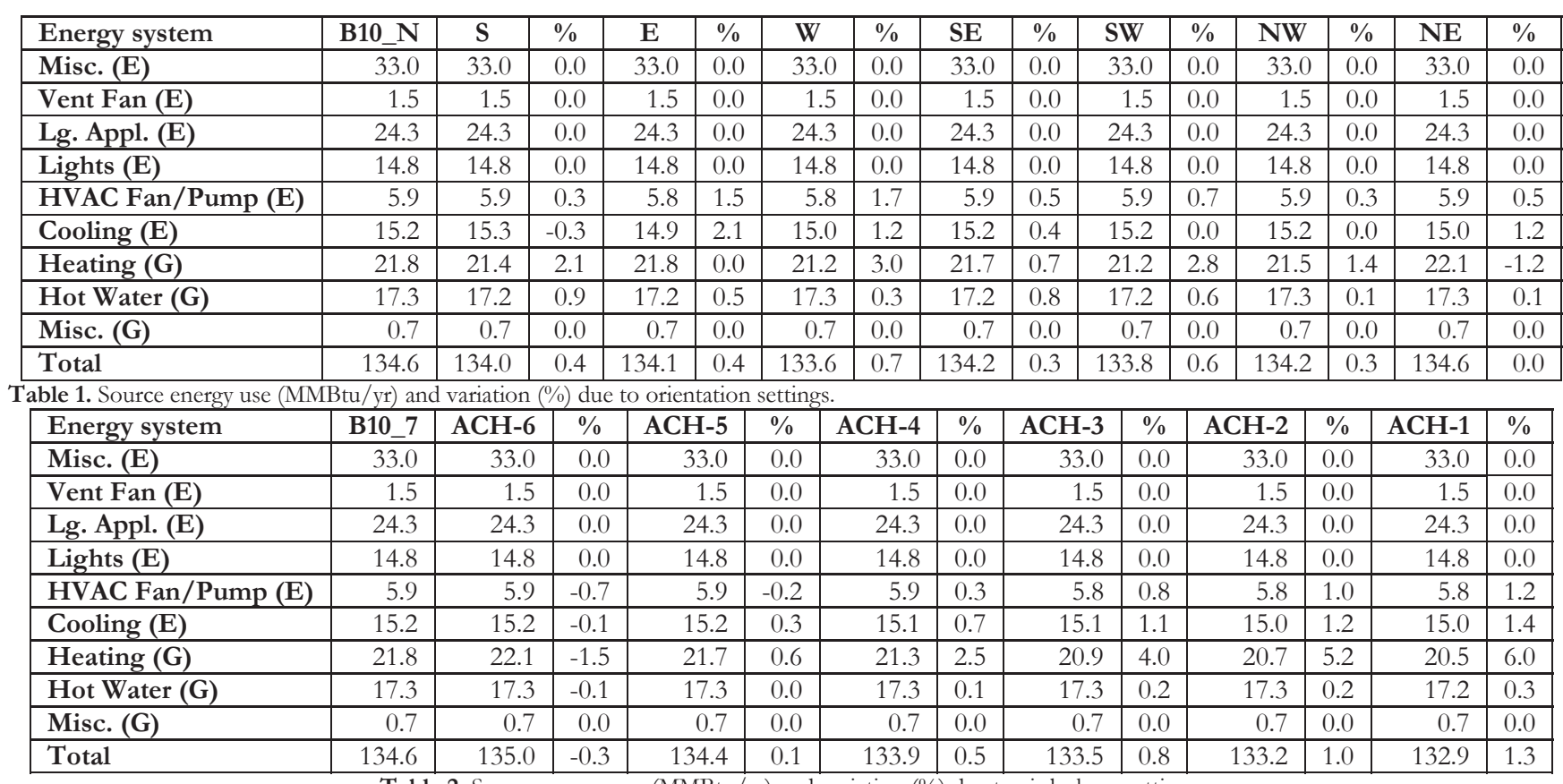

Table 2. Source energy use (MMBtu/yr) and variation (\%) due to air leakage settings.

\begin{tabular}{|l|r|r|c|r|c|}
\hline Energy system & B10_13 & A/C-14 & \% & A/C-15 & \% \\
\hline Misc. (E) & 33.0 & 33.0 & 0.0 & 33.0 & 0.0 \\
\hline Vent Fan (E) & 1.5 & 1.5 & 0.0 & 1.5 & 0.0 \\
\hline Lg. Appl. (E) & 24.3 & 24.3 & 0.0 & 24.3 & 0.0 \\
\hline Lights (E) & 14.8 & 14.8 & 0.0 & 14.8 & 0.0 \\
\hline HVAC Fan/Pump (E) & 5.9 & 5.9 & 0.0 & 5.9 & 0.0 \\
\hline Cooling (E) & 15.2 & 13.9 & 8.7 & 12.6 & 17.0 \\
\hline Heating (G) & 21.8 & 21.8 & 0.0 & 21.8 & 0.0 \\
\hline Hot Water (G) & 17.3 & 17.3 & 0.0 & 17.3 & 0.0 \\
\hline Misc. (G) & 0.7 & 0.7 & 0.0 & 0.7 & 0.0 \\
\hline Total & 134.6 & 133.3 & 1.0 & 132.0 & 1.9 \\
\hline
\end{tabular}

Table 3a. Source energy use (MMBtu/yr) and variation (\%) due to air conditioning efficiency.

\begin{tabular}{|c|c|c|c|c|c|c|c|}
\hline Energy system & B10_None & HP-13 & $\%$ & HP-14 & $\%$ & HP-15 & $\%$ \\
\hline Misc. (E) & 33.0 & 33.0 & 0.0 & 33.0 & 0.0 & 33.0 & 0.0 \\
\hline Vent Fan (E) & 1.5 & 1.5 & 0.0 & 1.5 & 0.0 & 1.5 & 0.0 \\
\hline Lg. Appl. (E) & 24.3 & 24.3 & 0.0 & 24.3 & 0.0 & 24.3 & 0.0 \\
\hline Lights (E) & 14.8 & 14.8 & 0.0 & 14.8 & 0.0 & 14.8 & 0.0 \\
\hline HVAC Fan/Pump (E) & 5.9 & 7.3 & -24.6 & 7.3 & -24.6 & 7.3 & -24.6 \\
\hline Cooling (E) & 15.2 & 15.4 & -1.1 & 14.2 & 6.5 & 13.6 & 10.7 \\
\hline Heating (E) & 0.0 & 16.9 & \multirow{2}{*}{22.7} & 15.2 & \multirow{2}{*}{30.4} & 14.5 & \multirow{2}{*}{33.7} \\
\hline Heating (G) & 21.8 & 0.0 & & 0.0 & & 0.0 & \\
\hline Hot Water (G) & 17.3 & 17.3 & 0.0 & 17.3 & 0.0 & 17.3 & 0.0 \\
\hline Misc. (G) & 0.7 & 0.7 & 0.0 & 0.7 & 0.0 & 0.7 & 0.0 \\
\hline Total & 134.6 & 131.2 & 2.5 & 128.4 & 4.6 & 127.0 & 5.6 \\
\hline
\end{tabular}

Table 3b. Source energy use (MMBtu/yr) and variation (\%) due to air source heat pump efficiency. 


\begin{tabular}{|l|r|r|r|r|r|r|r|r|r|}
\hline Energy system & B10_76/71 & $\mathbf{7 5 / 7 2}$ & \multicolumn{1}{|c}{$\boldsymbol{7}$} & $\mathbf{7 4 / 7 3}$ & $\mathbf{9}$ & $\mathbf{7 3 / 7 4}$ & \multicolumn{1}{c}{$\%$} & $\mathbf{7 2 / 7 5}$ & $\mathbf{\%}$ \\
\hline Misc. (E) & 33.0 & 33.0 & 0.0 & 33.0 & 0.0 & 33.0 & 0.0 & 33.0 & 0.0 \\
\hline Vent Fan (E) & 1.5 & 1.5 & 0.0 & 1.5 & 0.0 & 1.5 & 0.0 & 1.5 & 0.0 \\
\hline Lg. Appl. (E) & 24.3 & 24.3 & 0.0 & 24.3 & 0.0 & 24.3 & 0.0 & 24.3 & 0.0 \\
\hline Lights (E) & 14.8 & 14.8 & 0.0 & 14.8 & 0.0 & 14.8 & 0.0 & 14.8 & 0.0 \\
\hline HVAC Fan/Pump (E) & 5.9 & 6.7 & -13.6 & 7.6 & -29.0 & 8.5 & -44.7 & 9.3 & -58.2 \\
\hline Cooling (E) & 15.2 & 17.2 & -13.1 & 19.4 & -27.5 & 21.4 & -40.5 & 23.0 & -51.5 \\
\hline Heating (G) & 21.8 & 24.3 & -11.4 & 27.0 & -23.9 & 30.8 & -40.9 & 33.9 & -55.5 \\
\hline Hot Water (G) & 17.3 & 17.3 & 0.0 & 17.3 & 0.0 & 17.3 & 0.0 & 17.3 & 0.0 \\
\hline Misc. (G) & 0.7 & 0.7 & 0.0 & 0.7 & 0.0 & 0.7 & 0.0 & 0.7 & 0.0 \\
\hline Total & 134.6 & 139.9 & -3.9 & 145.7 & -8.2 & 152.3 & -13.2 & 158.0 & -17.4 \\
\hline
\end{tabular}

Table 4a. Source energy use (MMBtu/yr) and variation (\%) due to decrease in cooling and increase in heating setpoints.

\begin{tabular}{|l|r|r|r|r|r|r|r|}
\hline Energy system & B10_ 76/71 & $\mathbf{7 7 / 7 0}$ & \multicolumn{1}{|c}{$\mathbf{0}$} & $\mathbf{7 8 / 6 9}$ & \multicolumn{1}{c|}{$\mathbf{7}$} & $\mathbf{7 9 / 6 8}$ & \multicolumn{1}{c|}{} \\
\hline Misc. (E) & 33.0 & 33.0 & 0.0 & 33.0 & 0.0 & 33.0 & 0.0 \\
\hline Vent Fan (E) & 1.5 & 1.5 & 0.0 & 1.5 & 0.0 & 1.5 & 0.0 \\
\hline Lg. Appl. (E) & 24.3 & 24.3 & 0.0 & 24.3 & 0.0 & 24.3 & 0.0 \\
\hline Lights (E) & 14.8 & 14.8 & 0.0 & 14.8 & 0.0 & 14.8 & 0.0 \\
\hline HVAC Fan/Pump (E) & 5.9 & 5.2 & 12.6 & 4.5 & 23.8 & 3.9 & 34.0 \\
\hline Cooling (E) & 15.2 & 13.4 & 12.2 & 11.6 & 23.5 & 10.0 & 34.1 \\
\hline Heating (G) & 21.8 & 19.5 & 10.6 & 17.4 & 20.4 & 15.4 & 29.6 \\
\hline Hot Water (G) & 17.3 & 17.3 & 0.0 & 17.3 & 0.0 & 17.3 & 0.0 \\
\hline Misc. (G) & 0.7 & 0.7 & 0.0 & 0.7 & 0.0 & 0.7 & 0.0 \\
\hline Total & 134.6 & 129.7 & 3.6 & 125.1 & 7.1 & 120.9 & 10.2 \\
\hline
\end{tabular}

Table 4b. Source energy use (MMBtu/yr) and variation (\%) due to increase in cooling and decrease in heating setpoints.

\begin{tabular}{|c|c|c|c|c|c|c|c|c|c|}
\hline Energy System & B_10 Gas & GTWH & $\%$ & ESWH & $\%$ & ETWH & $\%$ & HPWH & $\%$ \\
\hline Misc. (E) & 33.0 & 33.0 & 0.0 & 33.0 & 0.0 & 33.0 & 0.0 & 33.0 & 0.0 \\
\hline Vent Fan (E) & 1.5 & 1.5 & 0.0 & 1.5 & 0.0 & 1.5 & 0.0 & 1.5 & 0.0 \\
\hline Lg. Appl. (E) & 24.3 & 24.3 & 0.0 & 24.3 & 0.0 & 24.3 & 0.0 & 24.3 & 0.0 \\
\hline Lights (E) & 14.8 & 14.8 & 0.0 & 14.8 & 0.0 & 14.8 & 0.0 & 14.8 & 0.0 \\
\hline HVAC Fan/Pump (E) & 5.9 & 5.9 & 0.2 & 5.9 & 0.2 & 5.9 & 0.2 & 5.9 & 0.5 \\
\hline Cooling (E) & 15.2 & 15.2 & 0.3 & 15.2 & 0.2 & 15.2 & 0.3 & 15.1 & 1.1 \\
\hline Heating (G) & 21.8 & 21.9 & -0.5 & 21.9 & -0.4 & 21.9 & -0.5 & 22.1 & -1.1 \\
\hline Hot Water (E) & 0.0 & 0.0 & \multirow{2}{*}{27.1} & 30.8 & \multirow{2}{*}{-77.9} & 30.2 & \multirow{2}{*}{-74.6} & 16.7 & \multirow{2}{*}{3.6} \\
\hline Hot Water (G) & 17.3 & 12.6 & & 0.0 & & 0.0 & & 0.0 & \\
\hline Misc. (G) & 0.7 & 0.7 & 0.0 & 0.7 & 0.0 & 0.7 & 0.0 & 0.7 & 0.0 \\
\hline Total & 134.6 & 130.0 & 3.4 & 148.1 & -10.0 & 147.6 & -9.7 & 134.0 & 0.4 \\
\hline
\end{tabular}

Table 5. Source energy use (MMBtu/yr) and variation (\%) due to water heating settings.

\begin{tabular}{|c|c|c|c|c|c|c|c|c|c|}
\hline Energy System & B_10 Suburban & City & $\%$ & Rural & $\%$ & Plains & $\%$ & Oceans & $\%$ \\
\hline Misc. (E) & 33.0 & 33.0 & 0.0 & 33.0 & 0.0 & 33.0 & 0.0 & 33.0 & 0.0 \\
\hline Vent Fan (E) & 1.5 & 1.5 & 0.0 & 1.5 & 0.0 & 1.5 & 0.0 & 1.5 & 0.0 \\
\hline Lg. Appl. (E) & 24.3 & 24.3 & 0.0 & 24.3 & 0.0 & 24.3 & 0.0 & 24.3 & 0.0 \\
\hline Lights (E) & 14.8 & 14.8 & 0.0 & 14.8 & 0.0 & 14.8 & 0.0 & 14.8 & 0.0 \\
\hline HVAC Fan/Pump (E) & 5.9 & 6.0 & -1.0 & 5.9 & 0.5 & 5.9 & 0.5 & 5.9 & -0.8 \\
\hline Cooling (E) & 15.2 & 15.6 & -2.6 & 15.0 & 1.7 & 14.8 & 2.7 & 14.7 & 3.4 \\
\hline Heating (G) & 21.8 & 21.2 & 3.1 & 22.5 & -2.9 & 23.1 & -6.0 & 24.6 & -12.6 \\
\hline Hot Water (G) & 17.3 & 17.2 & 0.5 & 17.4 & -0.3 & 17.4 & -0.6 & 17.5 & -1.1 \\
\hline Misc. (G) & 0.7 & 0.7 & 0.0 & 0.7 & 0.0 & 0.7 & 0.0 & 0.7 & 0.0 \\
\hline Total & 134.6 & 134.3 & 0.2 & 135.0 & -0.3 & 135.6 & -0.7 & 137.0 & -1.8 \\
\hline
\end{tabular}

With the idea of giving a visual representation of the results obtained from the sensitivity analysis, Figure 1 shows the total source energy use for each variation considered. For each series (labels B-10 and Table 1 through Table 6), the column bars have the same order from left to the right as the columns on the tables. 


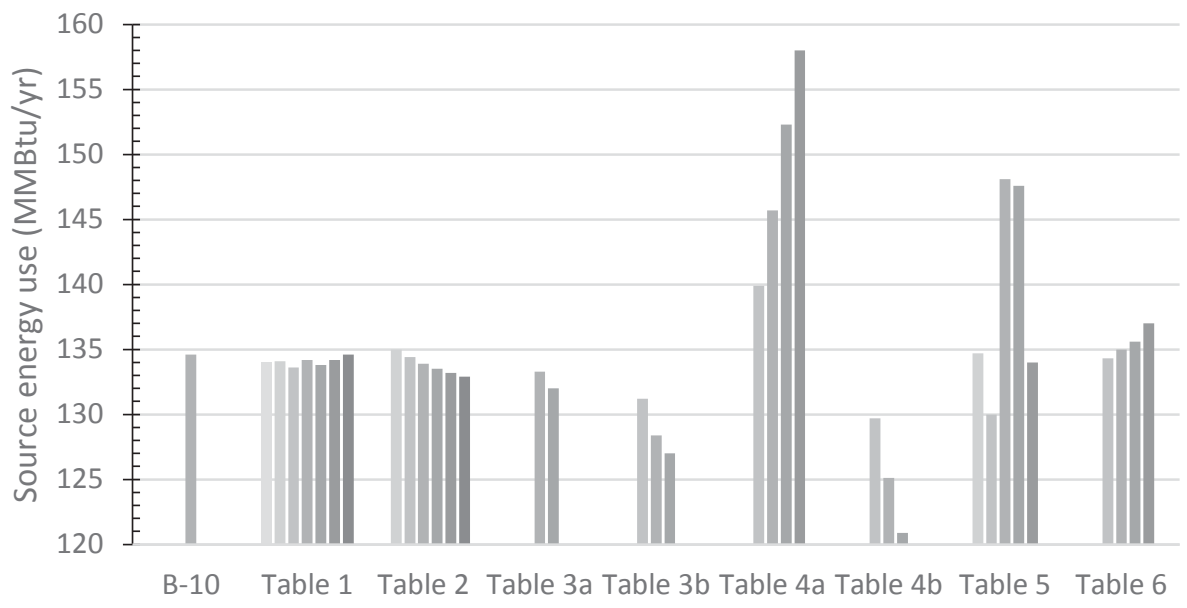

Figure 1. Total source energy use for each variation considered.

\section{CONCLUSION}

Building energy estimations for residential buildings are gaining a lot of importance due to the large energy consumption of the residential sector, which compares with the others sectors of the economy. This study provides the comparison of input parameters for the energy analysis of residential buildings. This study was intended to identify the most common and relevant input parameters for simulation of residential energy consumption. A model was developed in BEopt using information of the Building America B-10 benchmark and the TxAIRE House. The model was used to run simulations to perform sensitivity analysis of the most common input variables in selected software and webtools. The comparison of input parameters among the six tools investigated indicates that the common input parameters are building orientation, air leakage, space conditioning equipment, space conditioning schedule (thermostat set point), water heater, and terrain.

For the range of change in the input parameters considered in this study, it was found that the space conditioning schedule produced the highest variation in energy consumption. For a $4^{\circ} \mathrm{F}$ decrease in the cooling setpoint and $4^{\circ} \mathrm{F}$ increase in the heating setpoint, an increase of $17.4 \%$ was obtained for the annual energy source consumption. The second largest variation was found to be associated with the water heating equipment, and using the electric standard water heater produced an increase of $10 \%$ of the annual total energy use. Regarding water heaters, it is a good option to use gas tankless water heaters, as well, gas water heaters use less source energy than the electric water heaters. The third largest variation was found by the space conditioning equipment, which accounts for the efficiency of the equipment. Increasing the efficiency of the air conditioning from SEER 13 to SEER 15 a $1.9 \%$ reduction of source energy is obtained; while changing to a heat pump with SEER of 15 a $5.6 \%$ reduction is achieved. The other input parameters, orientation and air leakage, produced a maximum reduction of the annual source energy use of $0.3 \%$ and $1.3 \%$, respectively. The options for terrain indicates that the energy consumption due to HVAC systems will vary with the type of terrain. 


\section{REFERENCES}

1. Fumo, N. (2014) A review on the basics of building energy estimation, Renewable and Sustainable Energy Reviews 21, 53-60. doi:10.1016/j.rser.2013.11.040

2. National Resources Canada, http://oee.rncan.gc.ca/publications/statistics/trends11/chapter3.cfm (accessed May 2015)

3. National Renewable Energy Laboratory, U.S. Department of Energy, http:// wmw.nrel.gov/ (accessed May 2015)

4. National Resources Canada, Canada's CanmetENERGY, https://mww.nrcan.gc.ca/energy/offices-labs/canmet/ 5715 (accessed May 2015)

5. M. Zhao, H. M. Künzel, and F. Antretter (2015) Parameters influencing the energy performance of residential buildings in different Chinese climate zones, Energy and Buildings 96, 64-75. doi:10.1016/j.enbuild.2015.03.007

6. R. Arababadi, H. Naganathan, K. Parrish, and W.K. Chong (2015) Determining the Feasibility of Statistical Techniques to Identify the Most Important Input Parameters of Building Energy Models, Procedia Engineering 118, $1258-1265$. doi:10.1016/j.proeng.2015.08.478

7. International Energy Conservation Code, International Code Council, http://publicecodes.cyberregs.com/icod/iecc/index.htm (accessed on November 2015)

8. ASHARE Standard 90.1-2010, Energy Standard for Buildings except Low-Rise Residential Buildings.

9. Bryan Urban and Leon Glicksman (2007) A Simplified Rapid Energy Model and Interface for Nontechnical Users, Buildings X Conference, ASHRAE, Clearwater FL. Available at bttp://designadvisor.mit.edu/design/papers/Urban_Glicksman_ORNL_2007.pdf

10. A. Ioannou and L.C.M. Itard (2015) Energy performance and comfort in residential buildings: Sensitivity for building parameters and occupancy, Energy and Buildings 92, 216-233. doi:10.1016/j.enbuild.2015.01.055

11. Building Energy Software Tools Directory, Energy Efficiency and Renewable Energy, U.S. Department of Energy, http:// apps1.eere.energy.gov/buildings/tools_directory/ (accessed on May 2015)

12. BEopt (Building Energy Optimization), National Renewable Energy Laboratory, U.S. Department of Energy, http:// beopt.nrel.gov/ (accessed on May 2015)

13. Building America Program, Energy Efficiency and Renewable Energy, U.S. Department of Energy, http:/ / energy.gov/ eere/buildings/building-america-bringing-building-innovations-market (accessed May 2015).

14. TxAIRE Research and Demonstration Houses, The University of Texas at Tyler, https:/ / www.uttyler.edu/txaire/ houses/ (accessed May 2015)

15. EnergyPlus, Energy Efficiency and Renewable Energy, U.S. Department of Energy, http:// apps1.eere.energy.gov/buildings/energyplus/ (accessed April 2015)

16. EnergyGauge, Florida Solar Energy Center, http:/ / www.energygauge.com/ (accessed May 2015)

17. Home Energy Saver, Lawrence Berkeley National Laboratory, http:/ / homeenergysaver.lbl.gov/consumer/ (accessed May 2015)

18. Home Energy Yard Stick, Energy Star program, the U.S. Environmental protection Agency, https:/ / wmw.energystar.gov/index.cfm?fuseaction=home_energy_yardstick.showgetstarted (accessed March 2015)

19. Home Energy Scoring Tool, Lawrence Berkeley National Laboratory, http:// homeenergyscore.lbl.gov/ (accessed February 2015)

20. HOT2XP, Energy, Energy Resources, National Resources Canada, http:// wmw.nrcan.gc.ca/energy/software-tools/7445 (accessed May 2015)

21. HOT2XP, Energy, Energy Resources, National Resources Canada, http://wmw.nrcan.gc.ca/energy/offices-labs/canmet/5715 (accessed May 2015)

\section{ABOUT THE STUDENT AUTHOR}

Sheikh Tijan Tabban is currently pursuing his B.S. in Mechanical Engineering and a minor in Mathematics. He has been in the University of Texas at Tyler for two years. He worked as an intern for Shell marketing Gambia Ltd as a quality control specialist at their fuel depot. He just finished his automated guided cart capstone project, and currently seeking employment in the mechanical engineering industry.

\section{PRESS SUMMARY}

Estimation of energy consumption of residential buildings using software tools depends on building characteristics and operation, which are defined through input parameters. This study provides the comparison of input parameters for the energy analysis of residential buildings, with the intention of identifying the most common and important input parameters. 


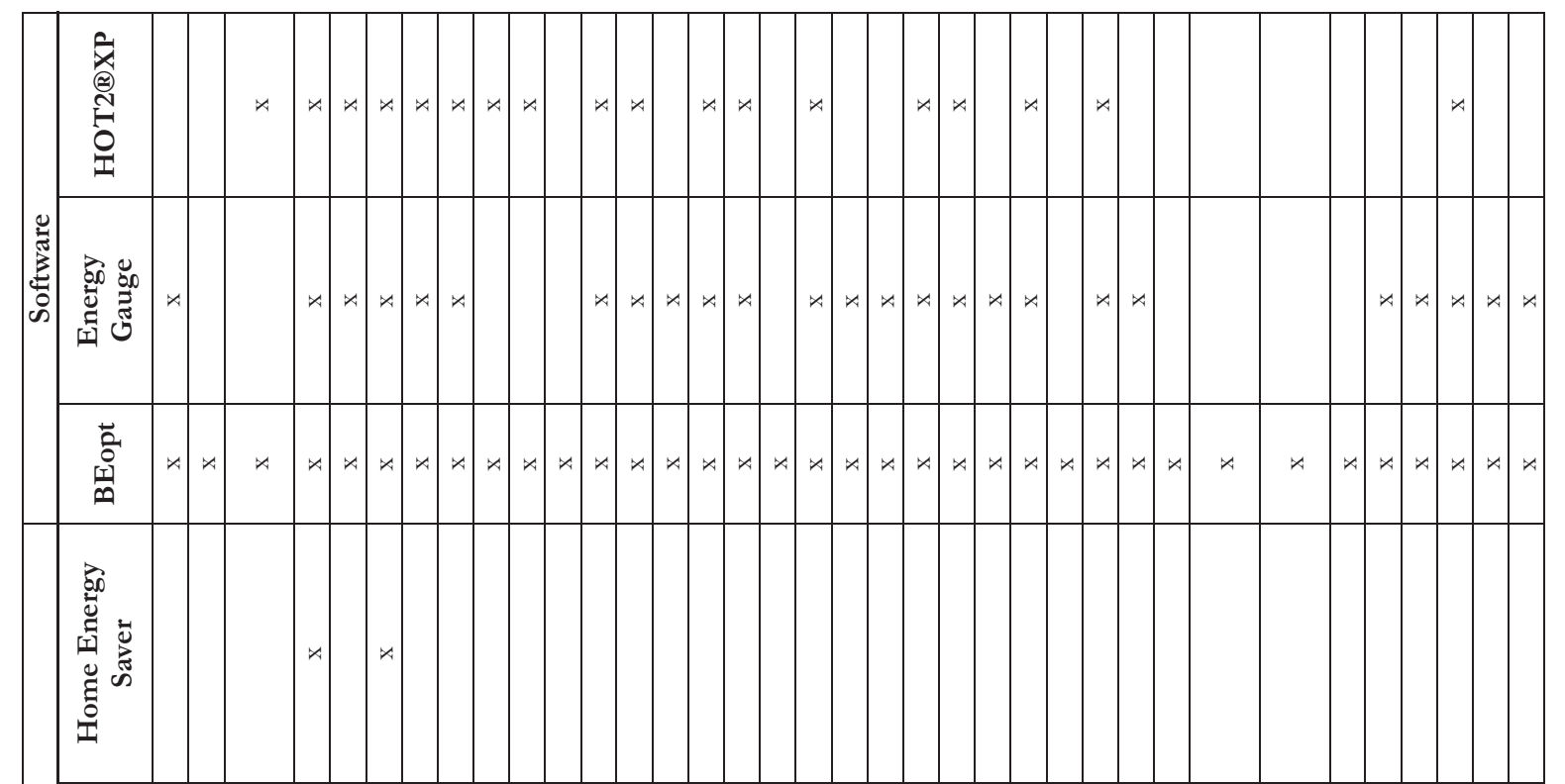



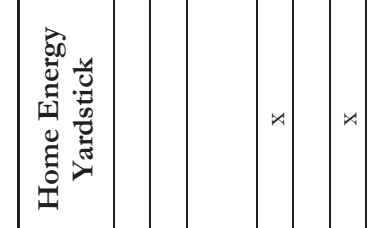

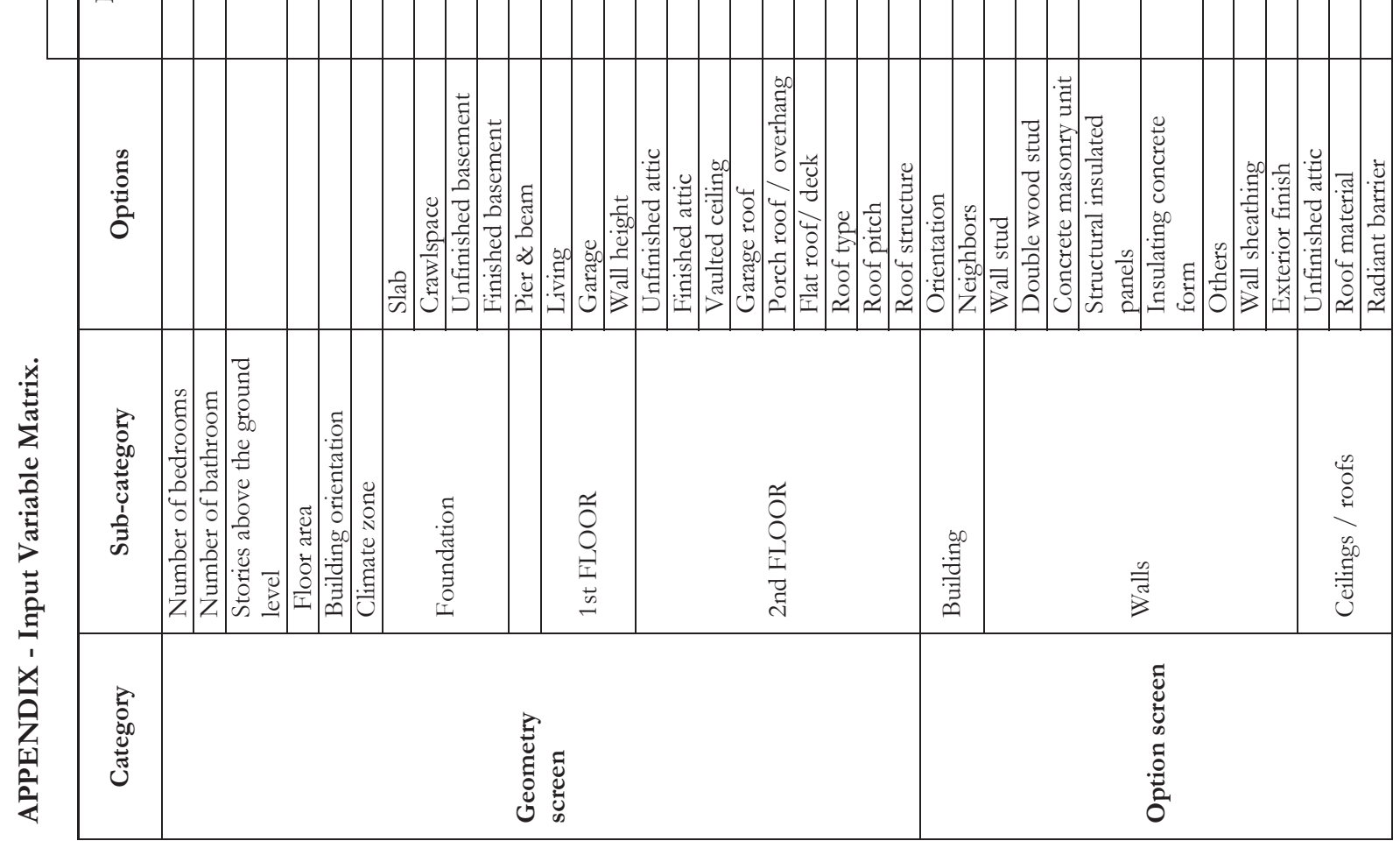






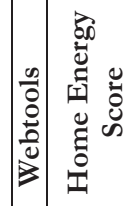

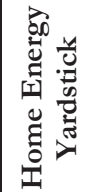

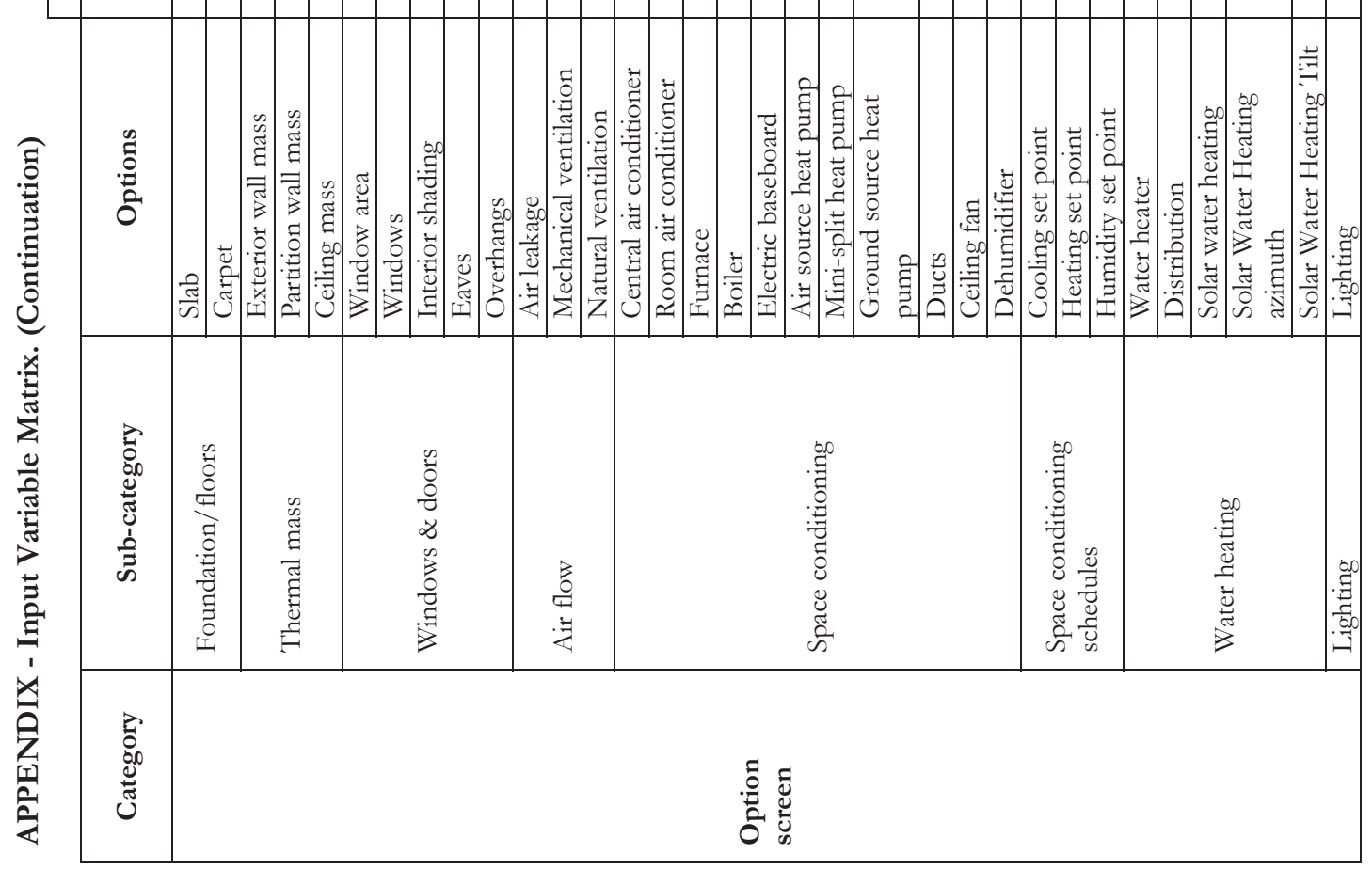








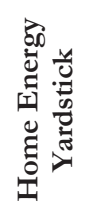

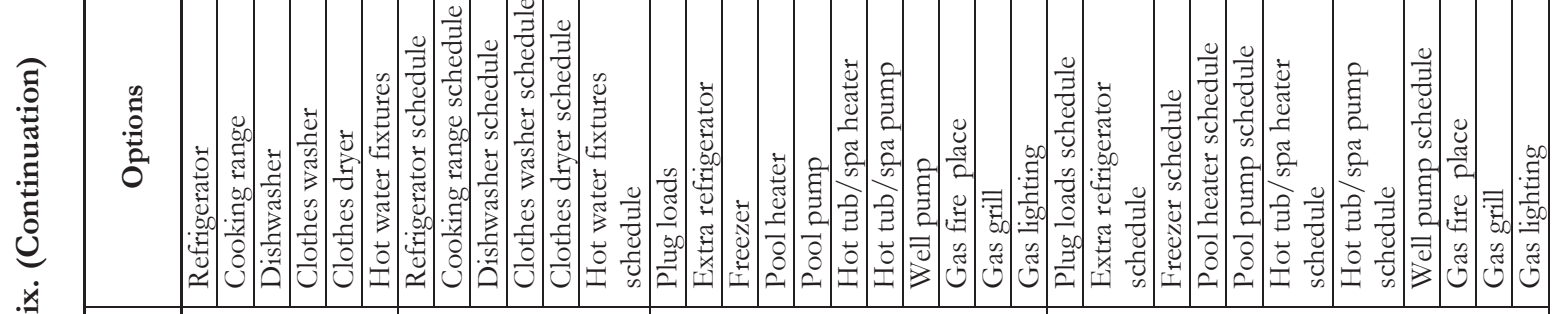

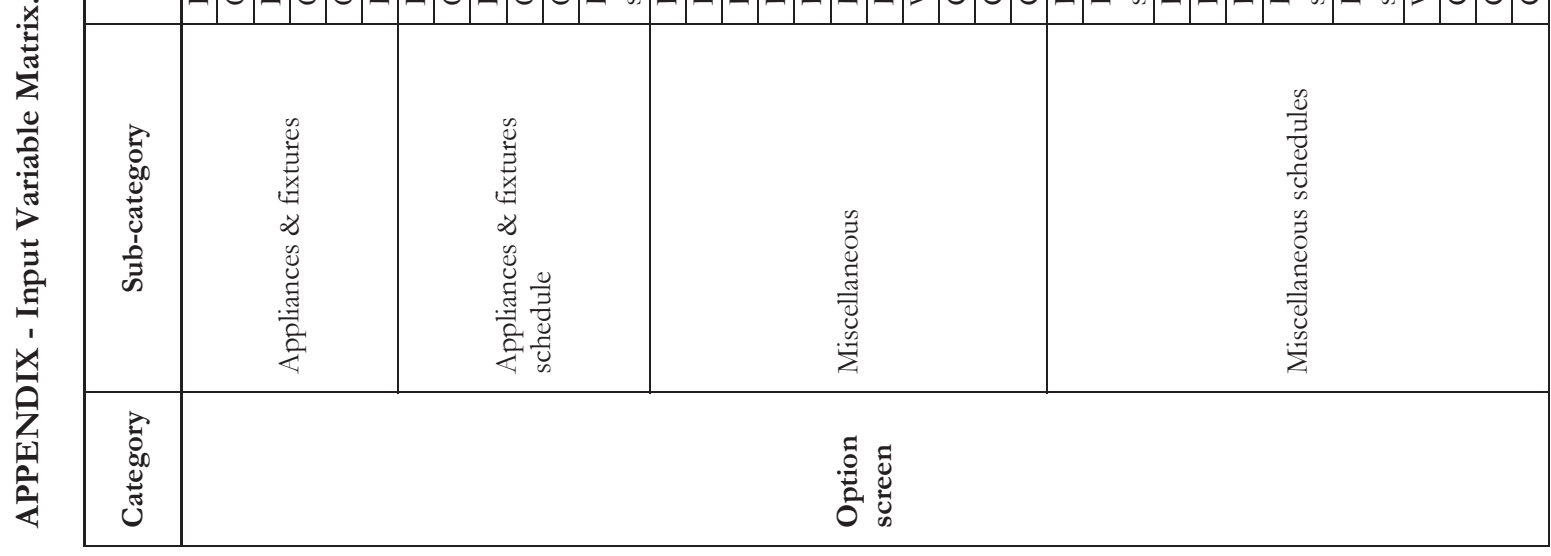




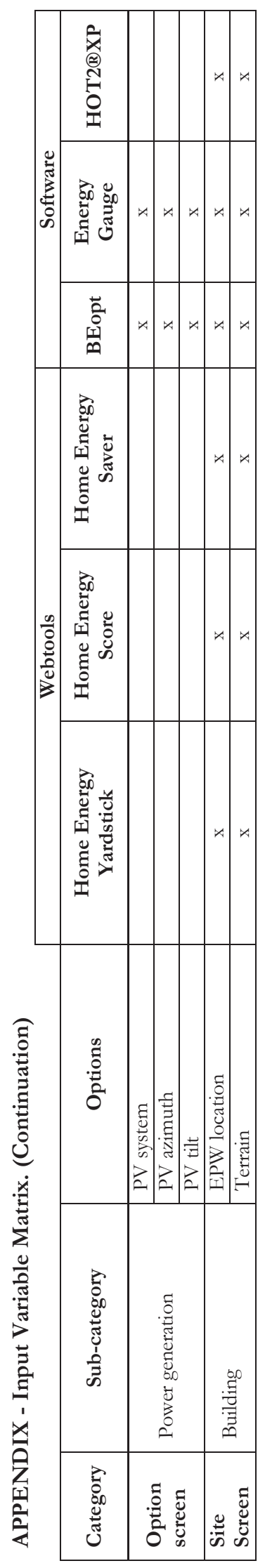

